\title{
Sunitinib in metastatic thymic carcinomas: Laboratory findings and initial clinical experience
}

\author{
P Ströbel $^{*, 1}$, R Bargou ${ }^{2}$, A Wolff ${ }^{2}$, D Spitzer ${ }^{3}$, C Manegold $^{4}$, A Dimitrakopoulou-Strauss ${ }^{5}$, L Strauss ${ }^{5}$, \\ C Sauer', F Mayer ${ }^{6}$, P Hohenberger ${ }^{7}$ and A Marx' \\ 'Institute of Pathology, University Medical Center Mannheim, University of Heidelberg, Theodor-Kutzer-Ufer I-3, 68I 35 Mannheim, Germany; \\ ${ }^{2}$ Division of Hematology and Medical Oncology, Department of Internal Medicine II, University of Würzburg, Klinikstraße 6, 97070 Würzburg, Germany; \\ ${ }^{3}$ Institute of General Medicine, Bodmanstr. 22, 87439 Kempten, Germany; ${ }^{4}$ Division of Thoracic Oncology, Department of Surgery, University Medical \\ Center Mannheim, University of Heidelberg, Theodor-Kutzer-Ufer I-3, 68135 Mannheim, Germany; ${ }^{5}$ Clinical Cooperation Unit Nuclear Medicine, \\ German Cancer Research Center, Heidelberg, Germany; ${ }^{6}$ Department of Medical Oncology, University of Tübingen, Tübingen, Germany; ${ }^{7}$ Division of \\ Surgical Oncology and Thoracic Surgery, Department of Surgery, University Medical Center Mannheim, University of Heidelberg, Theodor-Kutzer-Ufer I-3, \\ 68135 Mannheim, Germany
}

BACKGROUND: Thymic carcinoma (TC) is a rare aggressive tumour. Median survival with current treatments is only 2 years. Sunitinib is a multi-targeted tyrosine kinase inhibitor that has shown benefit in various other cancers.

METHODS: Laboratory analyses of snap-frozen tumour tissues were performed to detect activation and genetic mutations of receptor tyrosine kinases (RTKs) in TC samples. On the basis of molecular analyses showing activation of multiple RTKs in their tumour, four patients with metastatic TCs refractory to conventional therapies were treated with sunitinib according to standard protocols. RESULTS: RTK analysis in three of the patients showed activation of multiple RTKs, including platelet-derived growth factor- $\beta$ and vascular endothelial growth factor 3. Mutations of EGFR, c-KIT, KRAS, and BRAF genes were not found. Administration of sunitinib yielded a partial remission (lasting 2 to $18+$ months) according to the RECIST criteria in three patients and stable disease with excellent metabolic response in 18F-FDG-PET in another one. The overall survival with sunitinib treatment ranges from 4 to $40+$ months. Withdrawal of the drug in one patient prompted rapid tumour progression that could be controlled by re-administration of sunitinib.

CONCLUSIONS: Sunitinib is an active treatment for metastatic TC. A panel of molecular analyses may be warranted for optimal patient selection.

British Journal of Cancer (2010) I 03, 196-200. doi:I0.1038/sj.bjc.6605740 www.bjcancer.com

Published online 22 June 2010

(c) 2010 Cancer Research UK

Keywords: thymic carcinoma; thymoma; therapy; receptor tyrosine kinase; sunitinib; metastasis

Thymic carcinoma (TC) is a rare aggressive tumour of the thymus (Eng et al, 2004). It affects men nearly twice as often as women, across a wide age range (Travis et al, 2004). Patients often initially present with cough and chest pain. Further work-up usually reveals a mediastinal mass. Histologically, TCs are rather heterogeneous and resemble tumours found in other organs (Travis et al, 2004). The prognosis is generally poor, and the majority of patients develop recurrences. Lymph nodes, lungs, liver, and bones are common sites for metastases. Patients with TC have a median survival of 2 years (Eng et al, 2004).

The optimal management of TCs remains an unresolved question, because of their rarity and aggressiveness (Kurup and Loehrer, 2004). Complete surgical resection substantially improves survival rates, but this is not always possible, because of invasion of surrounding structures or metastasis (Wright and Kessler,

*Correspondence: Professor P Ströbel; E-mail: philipp.stroebel@umm.de Received 22 March 2010; revised 19 May 2010; accepted 20 May 20 I0; published online 22 June 2010
2005). Adjuvant radiation with $40-70 \mathrm{~Gy}$ often follows surgical resection, but a survival advantage for radiotherapy has not been clearly demonstrated (Korst et al, 2009). Chemotherapy with regimens containing cisplatin have often yielded partial remissions (Evans and Lynch, 2005), but some patients do not respond at all and most patients do not achieve long-lasting remission. Thus, many patients eventually cannot be helped by any currently available treatments, and they succumb to the tumour's rapid progression.

Targeted molecular therapy is a new paradigm in cancer treatment, in which drugs selectively interfere with molecules considered important in oncogenesis. Whereas conventional chemotherapy aims to kill all proliferating cells including tumours, targeted molecular therapy aims to disrupt cancer-specific signalling pathways involved in tumour growth and proliferation (Faivre et al, 2006). Compared with the toxicity of chemotherapy, targeted molecular therapies seem to be relatively tolerable (Rutkowski and Ruka, 2009). There are multiple types of targeted molecular therapies, but among them, multi-target tyrosine kinase inhibitors have received particular attention. Tyrosine kinases regulate important cell functions, including survival, 
differentiation, and proliferation (Faivre et al, 2006). When mutated or overexpressed, they have key roles in many cancers: increasing tumour cell growth and proliferation, inducing resistance to apoptosis, and promoting angiogenesis and metastasis.

Sunitinib (Pfizer, New York, NY, USA) is a potent multi-target tyrosine kinase inhibitor, designed to selectively block the intracellular receptor-binding sites of several tyrosine kinases: vascular endothelial growth factors 1-3 (VEGF1-3), FMS-like tyrosine kinase 3 (FLT3), stem cell growth factor (c-KIT), plateletderived growth factors- $\alpha$ and $-\beta(\mathrm{PDGF} \alpha-\beta)$, colony-stimulating factor 1 (CSF1), and the 'RET' receptor for glial-derived neurotrophic factors (Faivre et al, 2007). Inhibition of these tyrosine kinase receptors is believed to ultimately result in tumour regression primarily through anti-angiogenic effects and also through direct tumour cell apoptosis. In clinical trials, sunitinib has been reported to be beneficial against metastatic clear-cell renal carcinoma (Motzer et al, 2007), gastrointestinal stromal tumour (Demetri et al, 2006), and advanced pancreatic neuroendocrine tumours (Kulke et al, 2008). The most commonly reported adverse events (such as fatigue, diarrhoea, nausea, anorexia, skin discolouration, and hand-foot syndrome) have been reported as relatively tolerable (Faivre et al, 2007; Porta et al, 2007).

For TC, there have only been a few peer-reviewed journal papers on any of the new targeted molecular therapies. We previously reported a single case in which imatinib led to temporary regression of liver metastases and stabilisation of the primary TC (Strobel et al, 2004). Another case report briefly mentioned the unsuccessful last-resort use of imatinib in a paediatric patient (Kertesz et al, 2007). One paper reported a partial response of a malignant thymoma to the abl/src kinase inhibitor dasatinib (Chuah et al, 2006).

In addition, there have been two case reports on the successful usage of sorafenib in heavily pre-treated, chemotherapy-resistant metastatic patients (Bisagni et al, 2009; Li et al, 2009).

To our awareness, there have been no reports of using sunitinib against any tumours of the thymus. The aim of this paper is to report the clinical outcomes and laboratory findings from our initial usage of sunitinib in metastatic TCs.

\section{METHODS}

\section{Patients}

Tumours were classified according to criteria of the WHO classification (Travis et al, 2004). Patients with metastatic TCs refractory to conventional treatment were considered eligible for treatment with sunitinib and inclusion in this report. All patients provided informed consent for treatment and reporting of their data.

\section{Treatment}

Patients were treated by interdisciplinary teams experienced in the application of tyrosine kinase inhibitors. Dose selection of sunitinib was dependent on tumour load, tumour progression slope, and expected toxicity profile related to the patients' co-medication and medical history, not always following the $50 \mathrm{mg}$ per day, $4 / 2$ regimen (Faivre et al, 2007) (4 weeks on, 2 weeks off treatment, see details below). Toxicity and response were closely monitored, to adjust the dosage or cycle length if required. Other concurrent therapies were used whenever indicated. Tumour response was assessed according to the revised RECIST criteria (Eisenhauer et al, 2009). Further medical history and adverse events were charted.

\section{Laboratory analyses}

Native tumour samples were available from patients A-C and kept snap frozen and stored at $-80^{\circ} \mathrm{C}$ for molecular analyses. Paraffin sections were stained by a standard avidin-biotin peroxidase technique. Primary antibodies included CD5, c-KIT, and ki67.

The Human Phosopho-Receptor Tyrosine Kinase Array Kit (R\&D Systems, Wiesbaden, Germany) was used according to the manufacturer's instructions to simultaneously detect the relative tyrosine phosphorylation levels of 42 different receptor tyrosine kinases (RTKs), as described previously in more detail (Ball et al, 2007).

Both DNA and RNA were extracted and amplified by PCR using commercial kits (QiAamp DNA FFPE and RNeasy FFPE; Qiagen, Hilden, Germany) according to the manufacturer's instructions. $c$-KIT (exons 9, 11, 13, 17), EGFR (exons 18-21), KRAS (exon 2), and $B R A F$ (V600E) were sequenced according to standard procedures (details available upon request).

\section{RESULTS}

\section{Laboratory findings}

In addition to histomorphological criteria, CD5 and c-KIT were strongly expressed in all cases, providing very strong evidence that these were indeed primary TCs (Travis et al, 2004).

Case A mainly showed activation of the EGFR, with a very weak signal for the insulin receptor (IR), KIT, and Ephrin B2 (Figure 1). Case B showed strong activation of several RTKs, including IR and insulin-like growth factor receptor 1, fibroblast growth factor receptor 2, KIT, Erb4, and RET (Figure 1) Case C showed activation of ErB4, Tyro3/Dtk, and RON (Figure 1).

Using PCR and direct sequencing of the resulting amplification products, no mutations were found for $c-K I T, K R A S, B R A F$, or EGFR (not shown).

\section{Patients}

The patients' basic sociodemographic and clinical characteristics are presented in Table 1 . Three patients in Table 1 were metastatic at the initial diagnosis. The patients' earlier history of cancer and treatment is summarised in Table 2. In brief, all patients had already reached a point of having metastases not responding to established treatment options, before they were started on sunitinib.

\section{Clinical outcomes}

For patient A, sunitinib was administered for 2 years, 9 months at a dose of $50 \mathrm{mg}$ per day, taken continuously (never cycled with
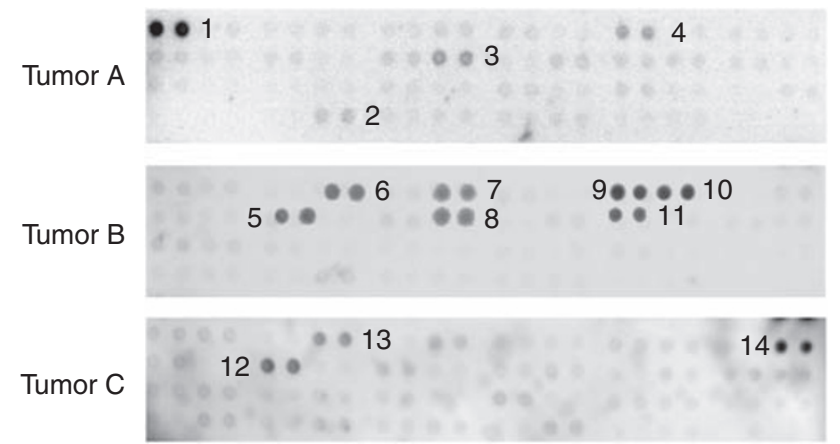

Figure I Phospho-protein arrays of tumour samples from patients $A-C$ with 42 spotted receptor tyrosine kinases (signal indicates activated protein). Tumour sample of patient A shows strong activation of EGFR (I) and weaker signals for EphB2 (2), KIT (3), and the insulin receptor (4). Tumour sample of patient B shows moderate signals for RON (5), Erb4 (6), FGFR2 (7), KIT (8), and strong signals for insulin receptor (9), IGFIR (I0), and RET (I I). Tumour sample of patient $C$ shows moderate signals for RON (I2), Erb4 (I3), and Tyro3/Dtk (14). 
Table I Patient sociodemographic and clinical characteristics

\begin{tabular}{lccllll}
\hline Case & Sex & $\begin{array}{c}\text { Age at diagnosis } \\
\text { (years) }\end{array}$ & $\begin{array}{l}\text { Stage } \\
\text { (initial diagnosis) }\end{array}$ & Histopathology & $\begin{array}{l}\text { Stage } \\
\text { (start of sunitinib) }\end{array}$ & Tumour grade \\
\hline $\mathrm{A}$ & $\mathrm{M}$ & 35 & $\mathrm{Nb}$ & Squamous cell & $\mathrm{IVb}$ & 2 \\
$\mathrm{~B}$ & $\mathrm{M}$ & 69 & $\mathrm{Na}$ & Squamous cell & $\mathrm{IVb}$ & 2 \\
$\mathrm{C}$ & $\mathrm{M}$ & 77 & $\|$ & Squamous cell & $\mathrm{Nb}$ & $\mathrm{N}$ \\
$\mathrm{D}$ & $\mathrm{F}$ & 28 & $\mathrm{Nb}$ & Undifferentiated & $\mathrm{Nb}$ & 3 \\
\hline
\end{tabular}

Table 2 Previous treatment and result of sunitinib therapy

\begin{tabular}{|c|c|c|c|c|}
\hline Patient & Previous treatment & $\begin{array}{l}\text { Extent of tumour at start of } \\
\text { sunitinib }\end{array}$ & Treatment result & $\begin{array}{l}\text { Survival } \\
\text { (sunitinib) }\end{array}$ \\
\hline A & $\begin{array}{l}\text { Systemic chemotherapy, PR for } 3 \text { months, } \\
\text { imatinib } 400 / 800 \text { mg PD }\end{array}$ & $\begin{array}{l}\text { Primary tumour liver metastases ( } 60 \% \mathrm{HR}) \\
\text { axillary, supraclavicular, and coeliac lymph } \\
\text { node metastases }\end{array}$ & $\begin{array}{l}\mathrm{SD}^{\mathrm{a}} \text { of primary tumour and hepatic } \\
\text { metastases, excellent metabolic } \\
\text { response (FDG-PET), PR }{ }^{\mathrm{a}} \text { of coeliac } \\
\text { lymph node metastases }\end{array}$ & OS $40+$ months \\
\hline B & $\begin{array}{l}\text { Primary tumour resection, radiation to } \\
\text { mediastinum DFS } 4 \text { years, Systemic } \\
\text { chemotherapy for liver metastases, PD }\end{array}$ & Liver metastases & $\mathrm{PR}^{\mathrm{a}}$ & PFS 18+ months \\
\hline C & Primary tumour resection, DFS 14 months & Bilateral lung metastases & $P R^{a}$ & PFS |4+ months \\
\hline $\mathrm{D}$ & $\begin{array}{l}\text { Systemic chemotherapy, radiation of retinal } \\
\text { metastases, PR for } 6 \text { months }\end{array}$ & $\begin{array}{l}\text { Primary tumour, multiple bone and lung } \\
\text { metastases (all PD) }\end{array}$ & $P^{a}$ for 2 months & OS 4 months \\
\hline
\end{tabular}

Abbreviations: $P R=$ partial remission; $P D=$ progressive disease; $H R=$ hepatic replacement; $S D=$ stable disease; $O S=$ overall survival; $D F S=$ disease-free survival; $\mathrm{PFS}=$ progression-free survival. ${ }^{a}$ Acc to RECIST (Response Evaluation Criteria In Solid Tumors) criteria.

'off' periods). After just 2 weeks, the patient's abdominal pain disappeared. The $18 \mathrm{~F}-\mathrm{FDG}-\mathrm{PET}$ scans showed reduced glucose metabolism of all liver metastases after 6 weeks in comparison with pre-treatment values. After 6 months, the vessel density calculated by FDG-PET of the liver metastases was reduced to $<20 \%$ of their pre-sunitinib levels (Figure 2A-B). As the primary tumour seemed to respond less to the treatment than the liver metastases, concurrent radionuclide treatment with DOTATOC was administered during the 4 th-11th months of sunitinib. Thereafter, the vessel density of the metastases was still very low, and the metastases were classified as stable disease according to RECIST (Eisenhauer et al, 2009). After 22 months of sunitinib treatment, the liver metastases started to progress again with new lesions; hence, selective infusional radiotherapy was started, resulting in a PR. Another 8 months later (4 2009), the primary tumour was completely resected, followed by $54 \mathrm{~Gy}$ irradiation of the mediastinum. As all known tumour lesions seemed to be under control, sunitinib was discontinued in 7 2009. Three months later, PET-CT showed massive progression of the hepatic metastases (Figure 2C) and lymph node metastases at the coeliac axis. Sunitinib was re-administered at $50 \mathrm{mg}$ per day in 10 2009. Two months later, a control PET-CT showed marked regression of all lesions, corresponding to PR (Figure 2D).

Patient B presented with asymptomatic liver metastases. Sunitinib was started at the registered $50 \mathrm{mg}$ per day, 4/2 regimen. The metastases were still progressing after one cycle but developed a PR after another three cycles (Figure $3 \mathrm{~A}$ and $\mathrm{B}$ ). After four cycles of $4 / 2$, the cycling schedule was slowed to $4 / 4$ because of side effects during the 'on' phase, which resolved during the 'off phase'. After 10 months of therapy, the cycling was slowed to $4 / 6$ for another two cycles, and further $4 / 8$ dosage thereafter. At all follow-up visits since the fifth cycle of sunitinib until the present time (i.e., for 18 months), the liver metastases were still in good partial remission, and there has been no evidence of relapse of the primary tumour (Figure 3C).

Patient $\mathrm{C}$ presented with several metachronous asymptomatic lung metastases. Owing to his significant co-medication for severe NYHA III problems and hypertension, sunitinib was started at a dose of $25 \mathrm{mg}$ per day. As the medication was well tolerated, the
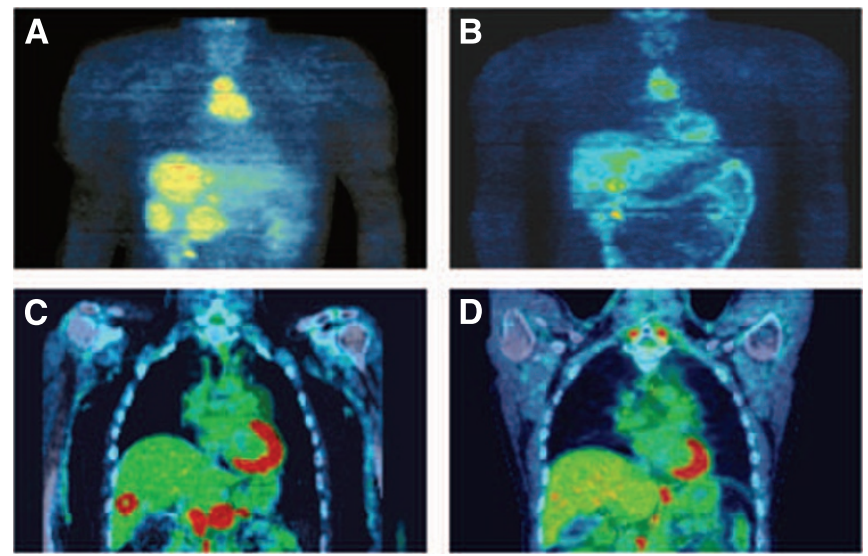

Figure 2 PET scans of the primary tumour and liver metastases from patient A. (A) Baseline just before initiating sunitinib. (B) After 6 months (in 4 2007) sunitinib. (C) Three months after withdrawal of sunitinib ( 10 2009) showing a highly enriched index metastasis. (D) The same lesion was undetectable 2 months after re-administration of sunitinib (I2 2009).

dose was escalated to $37.5 \mathrm{mg}$ per day after 4 weeks and antihypertensive medication was intensified. The CT controls at 7 months showed partial remission of his lung metastases (Figure $4 \mathrm{~A}-\mathrm{C}$ ). As the patient later on developed leukopenia with a WBC of $<1800$ cells per $\mathrm{ml}$ and anaemia, sunitinib was again decreased to $25 \mathrm{mg}$ per day after 9 months. After 14 months under sunitinib (2 2010), the patient is still in PR.

In patient $\mathrm{D}$, who suffered from a particularly aggressive, widely disseminated tumour at initial presentation, symptoms (such as shortness of breath) improved after 2 weeks of sunitinib with $50 \mathrm{mg}$ per day, 4/2 dosing. Restaging after 6 weeks showed a PR of the primary tumour and lung metastases. However, this was soon followed by rapid tumour progression, to which the patient succumbed 4 months after the start of sunitinib and 16 months after initial diagnosis. 

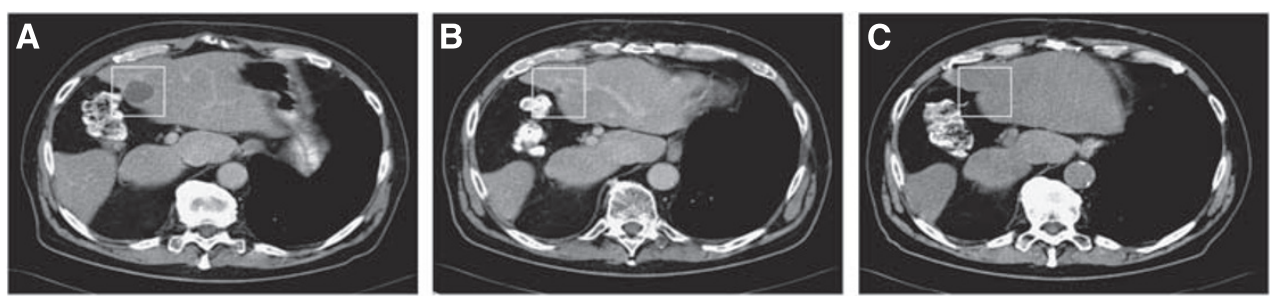

Figure 3 CT scans of a representative liver metastasis from patient B. (A) Liver metastasis at baseline just before initiating sunitinib. (B) Liver metastases after 6 months sunitinib. (C) Liver metastases after 18 months sunitinib.
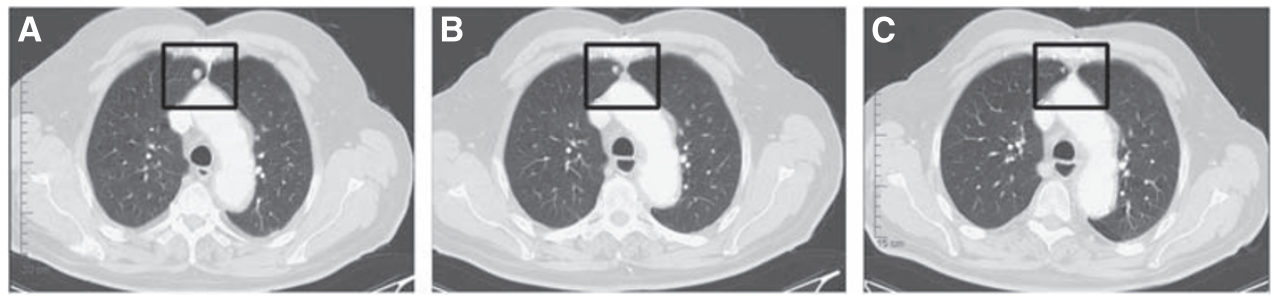

Figure 4 CT scans of an index lung metastasis from patient C. (A) Lung metastasis (square) at baseline just before initiating sunitinib. (B) Lung metastasis after 3 months sunitinib. (C) Lung metastasis after 7 months sunitinib.

\section{Side effects}

Commonly reported side effects of sunitinib were also observed in our patients. Nausea was present in three patients. Hypertension and fatigue were present in patients $\mathrm{A}$ and $\mathrm{C}$. Weakness and oedema were present in patients C and D. Patient D had some minor, non-relevant electrophysiological cardiac alterations, but no hypertension or haematological complications. Grade 2/3 hand-foot syndrome in patient B lead to prolonged 'off phases in the treatment cycles to allow for recovery.

\section{DISCUSSION}

Thymic carcinoma is a rare tumour that is difficult to treat in advanced stages. Cisplatin-based multi-agent chemotherapy can be beneficial, but often the responses do not last long. There is currently no other established second-line treatment for TC. Targeted molecular therapy could open new therapeutic options in these patients.

Our initial experience shows that sunitinib seems promising for patients with metastatic TC. The rationale for choosing this drug came from our observation that three of the available tumour samples showed simultaneous activation of multiple RTKs. Hence, it seemed reasonable to interfere with several of these processes concurrently to prevent tumour escape mechanisms through alternative signalling pathways (Faivre et al, 2006; Potapova et al, 2006).

The new targeted molecular therapies are clinically effective because they have been designed to disrupt the cellular signalling pathways involved in various aspects of oncogenesis, such as growth signal transduction, cell invasion, evasion of apoptosis, and metastatic dissemination. Sunitinib was originally designed and developed for its high potency against VEGFR2 and PDGFR- $\beta$ (Burstein et al, 2008), and it is known to block the intracellular ATP-binding sites of several other RTKs: VEGF1, VEGF3, FLT3, c-KIT, PDGF $\alpha$, CSF1, and RET (Faivre et al, 2007). Thus, on the basis of past scientific knowledge (Chow and Eckhardt, 2007) as well as our clinical observations and laboratory results, it seems plausible that the predominant mechanism of action of sunitinib in our patients was anti-angiogenesis, even though its main known targets were not prominently activated in the tumour samples studied herein. However in case A, the patient's PET scans showed a rapid and substantial reduction in tumour vessel density after the initiation of sunitinib, consistent with an anti-angiogenic mechanism of action. Many other RTKs also promote angiogenesis indirectly (Al-Nedawi et al, 2009) and thus could account for this finding. Taken together, the clinical observations, laboratory analyses, and previous molecular knowledge on sunitinib are consistent in supporting the view that sunitinib's effectiveness in these cases was due primarily to anti-angiogenesis.

Nonetheless, sunitinib may have had other mechanisms of action, in addition to anti-angiogenesis or instead of it. Sunitinib blocks many more RTKs than the literature or the manufacturer currently discusses. Furthermore, our array only tested for 42 of $\sim 300$ RTKs; hence, many other RTKs may have been activated in our patients. Further clinical studies will be required to analyse the underlying mechanisms more thoroughly.

Although our findings are limited by the small sample size, sunitinib seems to be a particularly good choice of secondline therapy for patients with metastatic TC. The tumours reported in this study were histologically and immunohistochemically comparable and representative for a majority of TCs in the broader population. Moreover, in line with previous reports (Tsuchida et al, 2008; Yoh et al, 2008), there were no mutations of $c$-KIT, KRAS, BRAF, or EGFR; therefore, apparently the effectiveness of sunitinib does not depend on such abnormalities.

Our initial observations suggest that sunitinib (and possibly also other multi-kinase inhibitors such as sorafenib (Bisagni et al, 2009)) may be more effective against TC than the disappointing results reported in the grey literature for single-target molecular therapies, such as gefinitinib (Kurup et al, 2005), erlotinib (Bedano et al, 2008), and imatinib (Salter et al, 2008). These earlier results seem plausible in the light of the broad and rather heterogeneous spectrum of activated RTKs in the few samples described in this study.

Our 'index' patient A provides very strong circumstantial evidence that sunitinib was able to control his disease over more than 3 years and even at relapse of sunitinib pre-treated metastases. Similar favourable findings in two other patients $(\mathrm{B}+\mathrm{C})$ indicate that sunitinib may be able to block tumour escape mechanisms and may be a promising option for long-term treatment. Patient D (with an unusually aggressive tumour) obtained a temporary partial remission, which we estimate prolonged her life by about 1-3 months. It is noteworthy that although tumours from patients A-C were 'classical' squamous 
cell TCs, the tumour from patient $\mathrm{D}$ was undifferentiated and had unusually high mitotic counts, prompting us to rule out EBV association or a so-called 'carcinoma with $\mathrm{t}(15 ; 19)$ translocation' (French et al, 2003) at initial presentation by respective molecular techniques.

In conclusion, sunitinib could be a promising new treatment option for TCs. Compared with many other tumours such as advanced prostate cancer (Dror Michaelson et al, 2009), metastatic colorectal cancer (Saltz et al, 2007), metastatic breast cancer (Burstein et al, 2008), or advanced non-small-cell lung cancer (Socinski et al, 2008), in which sunitinib was either inefficient or had only weak benefits were overridden by serious risks, TC seems to be one of the types of cancer that is responsive to sunitinib. It will be important to investigate whether patients with malignant thymomas may also benefit from this drug.

\section{ACKNOWLEDGEMENTS}

We thank Michael Hanna, PhD, (Mercury Medical Research and Writing) for providing publication consulting and medical writing services. This work was supported by grant no. 10-1740 from the Deutsche Krebshilfe and by Project grant 781025 of the Tumorzentrum Heidelberg/Mannheim.

\section{REFERENCES}

Al-Nedawi K, Meehan B, Kerbel RS, Allison AC, Rak J (2009) Endothelial expression of autocrine VEGF upon the uptake of tumor-derived microvesicles containing oncogenic EGFR. Proc Natl Acad Sci USA 106: $3794-3799$

Ball SG, Shuttleworth CA, Kielty CM (2007) Vascular endothelial growth factor can signal through platelet-derived growth factor receptors. J Cell Biol 177: 489-500

Bedano P, Perkins S, Burns M, Kessler KA, Nelson R, Schneider B, Risley L, Dropcho S, Loehrer Sr PJ (2008) A phase II trial of erlotinib plus bevacizumab in patients with recurrent thymoma or thymic carcinoma. J Clin Oncol 26(Suppl): No. 19087

Bisagni G, Rossi G, Cavazza A, Sartori G, Gardini G, Boni C (2009) Long lasting response to the multikinase inhibitor bay 43-9006 (Sorafenib) in a heavily pretreated metastatic thymic carcinoma. J Thorac Oncol 4: $773-775$

Burstein HJ, Elias AD, Rugo HS, Cobleigh MA, Wolff AC, Eisenberg PD, Lehman M, Adams BJ, Bello CL, DePrimo SE, Baum CM, Miller KD (2008) Phase II study of sunitinib malate, an oral multitargeted tyrosine kinase inhibitor, in patients with metastatic breast cancer previously treated with an anthracycline and a taxane. J Clin Oncol 26: 1810-1816

Chow LQ, Eckhardt SG (2007) Sunitinib: from rational design to clinical efficacy. J Clin Oncol 25: 884-896

Chuah C, Lim TH, Lim AS, Tien SL, Lim CH, Soong R, Lee F, Linn YC, Goh YT, Cheah FK, Loh AH (2006) Dasatinib induces a response in malignant thymoma. J Clin Oncol 24: e56-e58

Demetri GD, van Oosterom AT, Garrett CR, Blackstein ME, Shah $\mathrm{MH}$ Verweij J, McArthur G, Judson IR, Heinrich MC, Morgan JA, Desai J, Fletcher CD, George S, Bello CL, Huang X, Baum CM, Casali PG (2006) Efficacy and safety of sunitinib in patients with advanced gastrointestinal stromal tumour after failure of imatinib: a randomised controlled trial. Lancet 368: $1329-1338$

Dror Michaelson M, Regan MM, Oh WK, Kaufman DS, Olivier K, Michaelson SZ, Spicer B, Gurski C, Kantoff PW, Smith MR (2009) Phase II study of sunitinib in men with advanced prostate cancer. Ann Oncol 20: $913-920$

Eisenhauer EA, Therasse P, Bogaerts J, Schwartz LH, Sargent D, Ford R, Dancey J, Arbuck S, Gwyther S, Mooney M, Rubinstein L, Shankar L, Dodd L, Kaplan R, Lacombe D, Verweij J (2009) New response evaluation criteria in solid tumours: revised RECIST guideline (version 1.1). Eur J Cancer 45: $228-247$

Eng TY, Fuller CD, Jagirdar J, Bains Y, Thomas Jr CR (2004) Thymic carcinoma: state of the art review. Int J Radiat Oncol Biol Phys 59: $654-664$

Evans TL, Lynch TJ (2005) Role of chemotherapy in the management of advanced thymic tumors. Semin Thorac Cardiovasc Surg 17: $41-50$

Faivre S, Demetri G, Sargent W, Raymond E (2007) Molecular basis for sunitinib efficacy and future clinical development. Nat Rev Drug Discov 6: $734-745$

Faivre S, Djelloul S, Raymond E (2006) New paradigms in anticancer therapy: targeting multiple signaling pathways with kinase inhibitors. Semin Oncol 33: $407-420$

French CA, Miyoshi I, Kubonishi I, Grier HE, Perez-Atayde AR, Fletcher JA (2003) BRD4-NUT fusion oncogene: a novel mechanism in aggressive carcinoma. Cancer Res 63: $304-307$

Kertesz GP, Hauser P, Varga P, Dabasi G, Schuler D, Garami M (2007) Advanced pediatric inoperable thymus carcinoma (type $\mathrm{C}$ thymoma): case report on a novel therapeutic approach. J Pediatr Hematol Oncol 29: $774-775$

Korst RJ, Kansler AL, Christos PJ, Mandal S (2009) Adjuvant radiotherapy for thymic epithelial tumors: a systematic review and meta-analysis. Ann Thorac Surg 87: $1641-1647$

Kulke MH, Lenz HJ, Meropol NJ, Posey J, Ryan DP, Picus J, Bergsland E, Stuart K, Tye L, Huang X, Li JZ, Baum CM, Fuchs CS (2008) Activity of sunitinib in patients with advanced neuroendocrine tumors. J Clin Oncol 26: $3403-3410$

Kurup A, Burns M, Dropcho S, Pao W, Loehrer Sr PJ (2005) Phase II study of gefitinib treatment in advanced thymic malignancies. J Clin Oncol 23, 16s: No. 7068

Kurup A, Loehrer Sr PJ (2004) Thymoma and thymic carcinoma: therapeutic approaches. Clin Lung Cancer 6: 28-32

Li XF, Chen Q, Huang WX, Ye YB (2009) Response to sorafenib in cisplatinresistant thymic carcinoma: a case report. Med Oncol 26: 157-160

Motzer RJ, Hutson TE, Tomczak P, Michaelson MD, Bukowski RM, Rixe O, Oudard S, Negrier S, Szczylik C, Kim ST, Chen I, Bycott PW, Baum CM, Figlin RA (2007) Sunitinib versus interferon alfa in metastatic renal-cell carcinoma. $N$ Engl J Med 356: $115-124$

Porta C, Paglino C, Imarisio I, Bonomi L (2007) Uncovering Pandora's vase: the growing problem of new toxicities from novel anticancer agents. The case of sorafenib and sunitinib. Clin Exp Med 7: 127-134

Potapova O, Laird AD, Nannini MA, Barone A, Li G, Moss KG, Cherrington JM, Mendel DB (2006) Contribution of individual targets to the antitumor efficacy of the multitargeted receptor tyrosine kinase inhibitor SU11248. Mol Cancer Ther 5: 1280-1289

Rutkowski P, Ruka W (2009) Emergency surgery in the era of molecular treatment of solid tumours. Lancet Oncol 10: $157-163$

Salter J, Lewis D, Yiannoutsos C, Loehrer Sr PJ, Risley L, Chiorean E (2008) Imatinib for the treatment of thymic carcinoma. J Clin Oncol 26(Suppl): No. 8116

Saltz LB, Rosen LS, Marshall JL, Belt RJ, Hurwitz HI, Eckhardt SG, Bergsland EK, Haller DG, Lockhart AC, Rocha Lima CM, Huang X, DePrimo SE, Chow-Maneval E, Chao RC, Lenz HJ (2007) Phase II trial of sunitinib in patients with metastatic colorectal cancer after failure of standard therapy. J Clin Oncol 25: 4793-4799

Socinski MA, Novello S, Brahmer JR, Rosell R, Sanchez JM, Belani CP, Govindan R, Atkins JN, Gillenwater HH, Pallares C, Tye L, Selaru P, Chao RC, Scagliotti GV (2008) Multicenter, phase II trial of sunitinib in previously treated, advanced non-small-cell lung cancer. J Clin Oncol 26: 650-656

Strobel P, Hartmann M, Jakob A, Mikesch K, Brink I, Dirnhofer S, Marx A (2004) Thymic carcinoma with overexpression of mutated KIT and the response to imatinib. $N$ Engl J Med 350: 2625-2626

Travis WD, Brambilla E, Muller-Hermelink HK, Harris CCE (2004) Pathology and Genetics of Tumours of the Lung, Pleura, Thymus and Heart Vol. 7. World Health Organization Classification of Tumours Lyon: IARC Press

Tsuchida M, Umezu H, Hashimoto T, Shinohara H, Koike T, Hosaka Y, Eimoto T, Hayashi JI (2008) Absence of gene mutations in KIT-positive thymic epithelial tumors. Lung Cancer 62: $321-325$

Wright CD, Kessler KA (2005) Surgical treatment of thymic tumors Semin Thorac Cardiovasc Surg 17: 20-26

Yoh K, Nishiwaki Y, Ishii G, Goto K, Kubota K, Ohmatsu H, Niho S, Nagai K, Saijo N (2008) Mutational status of EGFR and KIT in thymoma and thymic carcinoma. Lung Cancer 62: 316-320 